\title{
APLIKASI REGRESI LINIER GANDA PADA BIDANG KEDOKTERAN GIGI
}

\author{
Ristya Widi Endah Yani \\ Bagian Ilmu Kesehatan Gigi Masyarakat Dan Pencegahan \\ Fakultas Kedokteran Gigi Universitas Jember
}

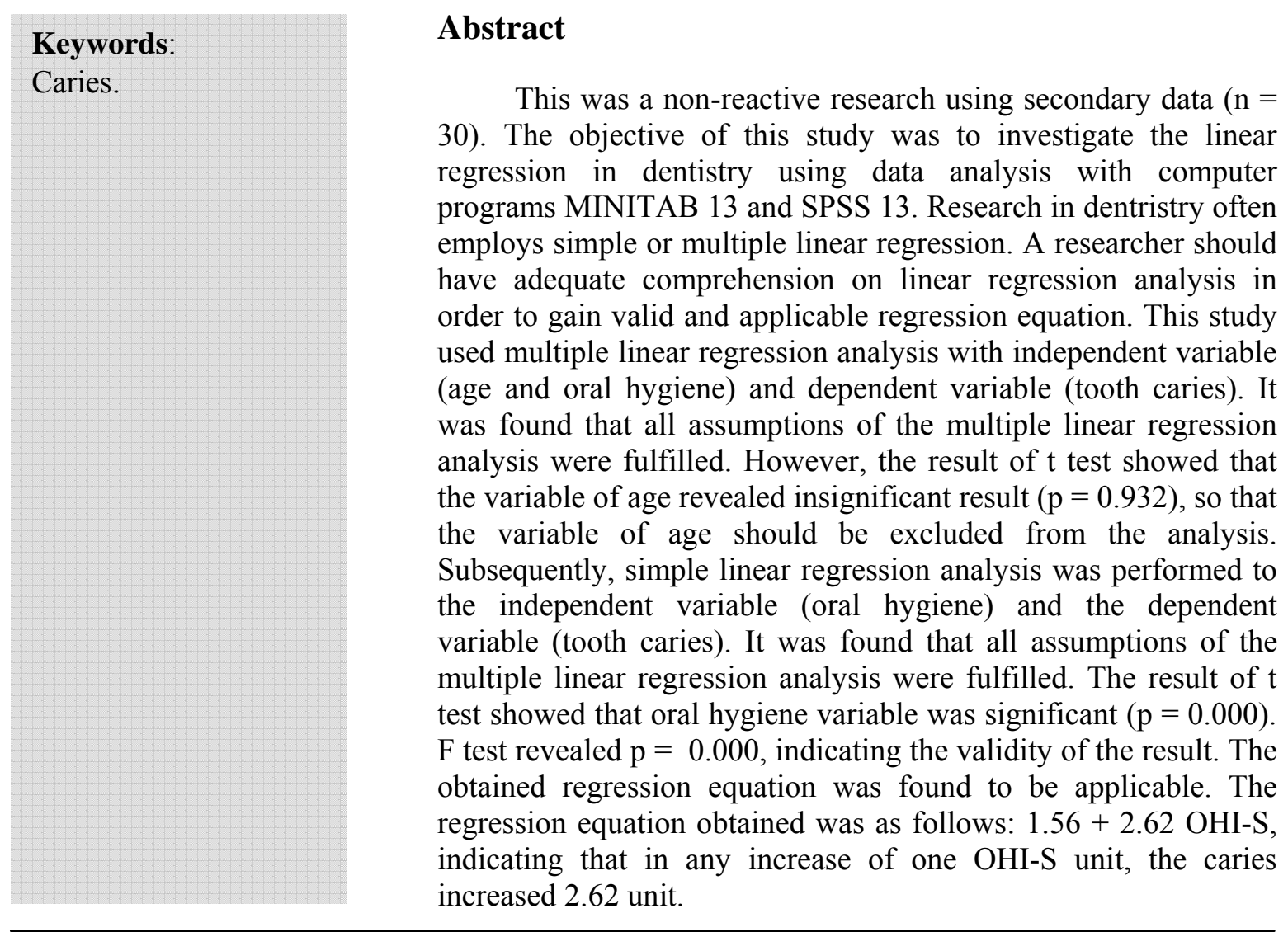

Alamat Korespondesi: Bagian Ilmu Kesehatan Gigi Masyarakat Dan PencegahanFakultas Kedokteran Gigi Universitas Jember 


\section{Pendahuluan}

Di bidang kedokteran gigi seringkali menggunakan analisis regresi linier sederhana dan ganda untuk penelitian. Sebagai peneliti seharusnya faham tentang analisis regresi linier sehingga persamaan regresi yang dihasilkan valid dan bisa diaplikasikan. Analisis regresi linier sederhana terdapat satu variabel dependen (Y) dan satu variabel independen (X). Analisis regresi linier ganda terdapat satu variabel dependen $(\mathrm{Y})$ dan lebih dari satu variabel independen $\left(\mathrm{X}_{\mathrm{i}}\right)$ di mana $\mathrm{i}=1,2,3 \ldots \mathrm{p}$, dengan tujuan memprediksi nilai Y (variabel dependen) berdasarkan nilai $\mathrm{X}$ (variabel independen). (Djarwanto, 1996).

Model dari analisis regresi linier ganda dapat ditulis sebagai berikut :

$$
Y=\beta_{0}+\beta_{1} X_{1}+\beta_{2} X_{2}+\Lambda+\beta_{k} X_{k}+\varepsilon
$$

(Menzefricke, 1995).

Asumsi Dalam Analisis Regresi Linier Ganda Beberapa asumsi yang mendasari analisis regresi linier ganda adalah sebagai berikut :

1. $\varepsilon_{\mathrm{i}}$ berdistribusi normal dan merupakan variabel random dengan $\left(\sum \varepsilon_{\mathrm{i}}\right)=0$. Dengan SPSS dapat dilakukan analisis deskriptif untuk melihat jumlah dan rerata nilai $\varepsilon$. Atau dengan mengujinya dengan uji kolmogorov smirnov

2. Tidak terdapat autokorelasi, dapat diuji dengan statistik Durban Watson (d)

3. Tidak terdapat heteroskesdastisitas. Cara melakukan uji ini adalah melakukan analisis korelasi Spearman antara nilai residu dengan masing-masing variabel independen.

4. Tidak terdapat multikolinieritas Ada beberapa cara untuk mendeteksi multikolinieritas diantaranya melihat korelasi antar variabel bebas. Cara lain dengan memeriksa Collinearity Diagnostics, dikatakan ada multikolinieritas bila nilai Eigenvalue mendekati 0 dan Condition Index lebih besar dari 15.

5. Linieritas. Mendeteksi linieritas dengan beberapa cara, diantaranya melihat diagram pencar (scatter plot) antara masing-masing variabel bebas dengan variabel tergantung. Cara lain melihat plot nilai residu dengan variabel bebas (Wibowo, dkk., 2006).

Pada umumnya penelitian di bidang kesehatan sering menggunakan analisis regresi linier ganda yang obyeknya manusia sebagai mahluk sosial beserta lingkungannya.

Sebagai aplikasi dalam penelitian ini digunakan data tentang pengaruh umur dan kebersihan gigi dan mulut terhadap karies gigi.

\section{Umur}

Newburn (1977) dalam Suwelo (1992) mengatakan karies gigi merupakan penyakit yang berhubungan dengan banyak faktor (multiple factors) yang saling mempengaruhi. Ada tiga faktor utama yaitu gigi dan saliva, mikroorganisme, dan substrat serta waktu. Selain faktor langsung di dalam mulut yang berhubungan dengan karies, terdapat pula faktor tidak langsung (faktor resiko luar), yaitu faktor predisposisi dan faktor penghambat terjadinya karies. Faktor luar antara lain usia, jenis kelamin, tingkat pendidikan, tingkat ekonomi, lingkungan, sikap dan perilaku yang berhubungan dengan kesehatan gigi. Anak yang pengaruh faktor resiko terjadinya karies kuat akan menunjukkan jumlah karies lebih besar dibanding yang kurang kuat pengaruhnya (Finn, 1977; Powell, 1980; Wycott, 1980 dalam Suwelo (1992).

\section{Kebersihan Gigi dan Mulut}

Mulut merupakan suatu tempat yang amat ideal bagi perkembangan bakteri, karena temperatur, kelembaban dan makanan yang cukup tersedia disana. Bakteri inilah yang berpengaruh pada kesehatan gigi dan mulut (Tarigan, 1990).

Menurut Carranza (1990), kebersihan gigi dan mulut ditentukan oleh adanya penumpukan sisasisa makanan (food debris), plak, kalkulus, materia alba dan stain pada permukaan gigi.

Pada penelitian ini mengggunakan OHI$\mathrm{S}$, dimana hasil dari penjumlahan skor DI-S (Debris Index Simplified) dan CI-S (Calculus Index Simplified). 


\section{Karies Gigi}

Menurut Kidd dan Bechal (1992), karies merupakan suatu penyakit jaringan keras gigi yaitu email, dentin dan sementum, yang disebabkan oleh aktifitas suatu jasad renik dalam karbohidrat yang diragikan. Newbrun (1978), mengatakan bahwa karies gigi adalah proses patologis berupa kerusakan yang terbatas di jaringan gigi mulai dari email terus ke dentin. Ford (1993), proses terjadinya karies gigi didalam rongga mulut dimana substrat (gula) dimetabolisme oleh bakteri dalam plak sehingga melarutkan email

Indeks karies gigi adalah angka yang menunjukkan secara klinis penyakit karies gigi. Indeks karies yang biasa dipakai adalah DMF-T digunakan untuk memeriksa gigi permanen dan def-t untuk gigi sulung.

Berdasarkan latar belakang di atas, maka dapat dirumuskan masalah, sebagai berikut : "Bagaimanakah penerapan regresi linier ganda di bidang kedokteran gigi?"

Tujuan dari penelitian ini adalah untuk mengkaji regresi linier ganda di bidang kedokteran gigi, sedangkan manfaat dari penelitian ini adalah mengetahui cara penyelesaian regresi linier di bidang kedokteran gigi

\section{Metode}

Suatu rancangan penelitian non reaktif (non reactive research) dengan menggunakan data sekunder (Neuman, 2006). Variabel yang digunakan dalam penelitian ini adalah variabel independen (umur dan kebersihan mulut) dan variabel dependen (karies gigi). Sumber Data berupa data sekunder (hasil penelitian Handayani (2007), dengan judul "Erupsi Gigi Permanen Dan Kesehatan Rongga Mulut Pada Anak Sekolah Dasar Di Daerah Endemik Gondok Kabupaten Jember"). Teknik Analisis Data dilakukan dengan komputer (MINITAB 13, SPSS 13).

\section{Hasil}

Data dirandom sebanyak 30 dari 100 data sekunder. Data di analisis regresi linier ganda, output yang dihasilkan diuji asumsi-asumsinya. Setelah itu barulah dihasilkan persamaan regresi yang valid.

Menentukan Persamaan Regresi Dengan Analisis Regresi Linier Ganda

\section{Regression Analysis: def versus umur, OHI-S}

The regression equation is

$\mathrm{def}=1.85-0.0035$ umur $+2.62 \mathrm{OHI}-\mathrm{S}$

Predictor Coef SE Coef T

$\begin{array}{lllll}\text { Constant } & 1.854 & 3.466 & 0.53 & 0.597\end{array}$

$\begin{array}{lllll}\text { umur } & -0.00351 & 0.04078 & -0.09 & 0.932\end{array}$

$\begin{array}{lllll}\text { OHI-S } & 2.6220 & 0.4387 & 5.98 & 0.000\end{array}$

$\mathrm{S}=1.173 \quad \mathrm{R}-\mathrm{Sq}=56.9 \% \quad \mathrm{R}-\mathrm{Sq}(\mathrm{adj})=53.8 \%$

Analysis of Variance

$\begin{array}{llllll}\text { Source } & \text { DF } & \text { SS } & \text { MS } & \text { F } & \text { P }\end{array}$

$\begin{array}{llllll}\text { Regression } & 2 & 49.147 & 24.573 & 17.86 & 0.000\end{array}$

$\begin{array}{lll}\text { Residual Error } & 27 & 37.153 \quad 1.376\end{array}$

$\begin{array}{lll}\text { Total } & 29 & 86.300\end{array}$

Source DF Seq SS

$\begin{array}{lll}\text { umur } & 1 & 0.001\end{array}$

OHI-S $\quad 1 \quad 49.146$

Unusual Observations

Obs umur def Fit SE Fit Residual St Resid

$\begin{array}{lllllll}25 & 77.0 & 8.000 & 5.517 & 0.480 & 2.483 \\ 2.32 \mathrm{R} & & & & & \\ 29 & 74.0 & 6.000 & 6.839 & 0.709 & -0.839 & - \\ 0.90 \mathrm{X} & & & & & \end{array}$

$\mathrm{R}$ denotes an observation with a large standardized residual

$\mathrm{X}$ denotes an observation whose $\mathrm{X}$ value gives it large influence.

Durbin-Watson statistic $=2.11$

Beberapa uji asumsi :

1. $\varepsilon_{i}$ berdistribusi normal dan $\varepsilon$ merupakan variabel random dengan $\left(\sum \varepsilon_{i}\right)=0$

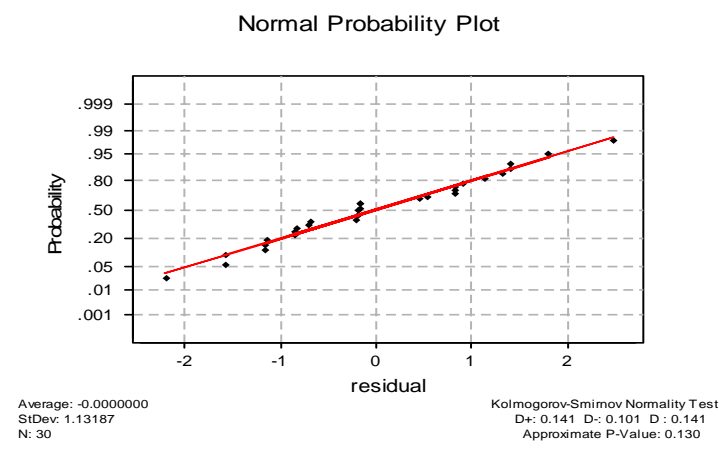


Dari uji kolmogorov smirnov dihasilkan "Approximate P-Value" = 0.130. Residual berdistribusi normal

2. Homoskedasitas

\begin{tabular}{|ll|r|r|r|}
\multicolumn{6}{|c|}{ Correlations } \\
\hline & & umur resp & OHI-S resp & residual \\
\hline Spearman's rho umur resp & Correlation Coefficien & 1.000 & .039 & .025 \\
& Sig. (2-tailed) &. & .838 & .897 \\
& $\mathrm{~N}$ & 30 & 30 & 30 \\
\cline { 2 - 5 } & OHI-S resp Correlation Coefficien & .039 & 1.000 & -.011 \\
& Sig. (2-tailed) & .838 &. & .953 \\
& $\mathrm{~N}$ & 30 & 30 & 30 \\
\cline { 2 - 6 } & Correlation Coefficien & .025 & -.011 & 1.000 \\
& Sig. (2-tailed) & .897 & .953 &. \\
& $\mathrm{~N}$ & 30 & 30 & 30 \\
\hline
\end{tabular}

Dari uji korelasi Spearman's, tidak terdapat korelasi antara residual dengan variabel umur ("Sig" = 0.897), residual dengan variabel OHI-S ("Sig" = 0.953). Sehingga dikatakan tidak terjadi heteroskedastisitas.

3. Tidak ada otokorelasi

Asumsi ini dilihat dengan membandingkan nilai pada tabel Durbin Watson dengan nilai Durbin Watson hasil perhitungan. Untuk uji 2 arah

$\mathrm{H}_{1}: \rho \neq 0$. Tolak $\mathrm{H}_{0}$ pada taraf $2 \alpha$ jika $\mathrm{d}<\mathrm{du}$ atau $4-\mathrm{d}<\mathrm{du}$

$\mathrm{N}($ besar sampel $)=30, \mathrm{k}($ variabel independen $)=2$ Nilai Durbin Watson dari perhitungan $(\mathrm{d})=2.11$

Nilai Durbin Watson pada tabel untuk du $=1.57$ (lihat tabel Durbin Watson)

$2.11>1.57$ atau $4-2.11>1.57 \rightarrow 1.89>1.57$.

Kesimpulan : karena $\mathrm{d}>\mathrm{du}$ atau $4-\mathrm{d}>\mathrm{du}$, maka terima Ho. Artinya tidak ada korelasi antar residu.

4. Tidak ada multikolinieritas

\begin{tabular}{|ll|r|r|}
\multicolumn{4}{|c}{ Correlations } \\
\hline & & umur resp & OHI-S resp \\
\hline umur resp & Pearson Correlation & 1 & .010 \\
& Sig. (2-tailed) & & .956 \\
& $\mathrm{~N}$ & 30 & 30 \\
\hline OHI-S resp & Pearson Correlation & .010 & 1 \\
& Sig. (2-tailed) & .956 & \\
& $\mathrm{~N}$ & 30 & 30 \\
\hline
\end{tabular}

Dari uji korelasi Pearson tidak didapatkan korelasi antara variabel umur dengan OHIS.("Sig" = 0.956). Kesimpulan tidak terdapat multikolinieritas.
5. Linieritas
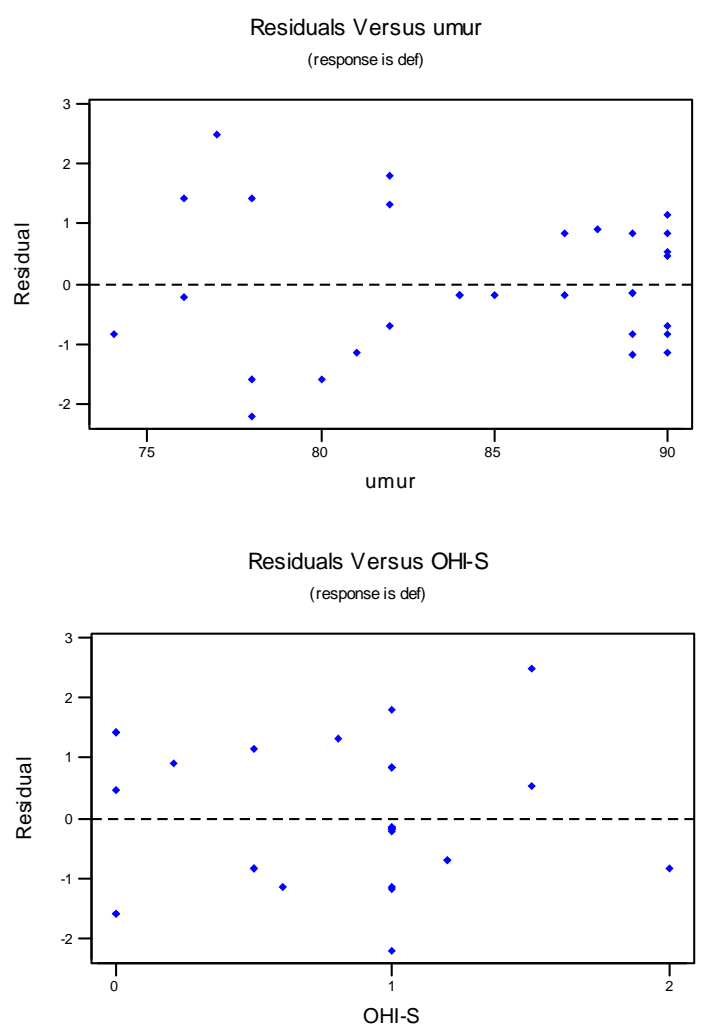

Dari gambar diatas : Titik-titik plot tersebar disekitar nilai 0 , dikatakan terdapat linieritas. Pada analysis of variance dihasilkan P-Value = 0.000. Pada uji t nilai "P-Value" untuk variabel umur tidak signifikan ("Sig" = 0.932), sedangkan "P-Value" untuk variabel OHI-S signifikan ("Sig" = 0.000). Sehingga variabel umur harus dikeluarkan dari analisis.

Berikut ini hasil analisis regresi linier sederhana dengan satu variabel dependen (karies) dan satu variabel independen (OHI-S).

\section{Regression Analysis: def versus OHI-S}

The regression equation is def $=1.56+2.62 \mathrm{OHI}-\mathrm{S}$

Predictor Coef SE Coef T P

$\begin{array}{lllll}\text { Constant } & 1.5581 & 0.4101 & 3.80 & 0.001\end{array}$

$\begin{array}{lllll}\text { OHI-S } & 2.6216 & 0.4309 & 6.08 & 0.000\end{array}$

$\mathrm{S}=1.152 \quad \mathrm{R}-\mathrm{Sq}=56.9 \% \quad \mathrm{R}-\mathrm{Sq}(\operatorname{adj})=55.4 \%$

Analysis of Variance

$\begin{array}{llllll}\text { Source } & \text { DF } & \text { SS } & \text { MS } & F & P\end{array}$

$\begin{array}{llllll}\text { Regression } & 1 & 49.137 & 49.137 & 37.02 & 0.000\end{array}$

$\begin{array}{lll}\text { Residual Error } & 28 \quad 37.163 \quad 1.327\end{array}$

Total $\quad 29 \quad 86.300$ 
Unusual Observations

Obs OHI-S def Fit SE Fit Residual St Resid

$\begin{array}{lllllll}25 & 1.50 & 8.000 & 5.491 & 0.362 & 2.509 & 2.29 \mathrm{R}\end{array}$

$\begin{array}{lllllll}29 & 2.00 & 6.000 & 6.801 & 0.551 & -0.801 & -0.79 \mathrm{X}\end{array}$

$\mathrm{R}$ denotes an observation with a large standardized residual

$\mathrm{X}$ denotes an observation whose $\mathrm{X}$ value gives it large influence.

Durbin-Watson statistic $=2.11$

Beberapa uji asumsi :

1. $\varepsilon_{i}$ berdistribusi normal dan $\varepsilon$ merupakan variabel random dengan $\left(\sum \varepsilon_{i}\right)=0$

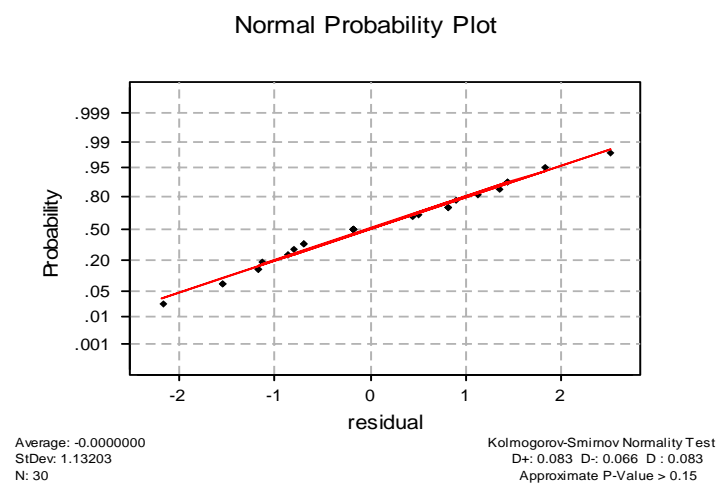

Dari uji kolmogorov smirnov dihasilkan "Approximate P-Value" $>0.15$. Residual berdistribusi normal

2. Homoskedasitas

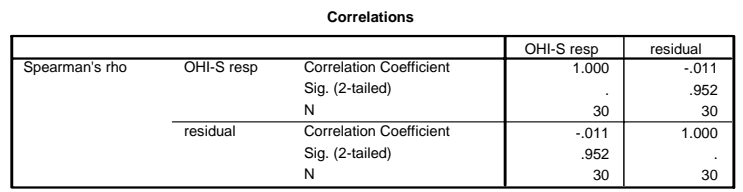

Dari uji korelasi Spearman's, dihasilkan korelasi yang tidak signifikan antara residual dengan variabel OHI-S ("Sig" = 0.952). Sehingga dikatakan tidak terjadi heteroskedastisitas.

\section{Tidak ada otokorelasi}

Asumsi ini dilihat dengan membandingkan nilai pada tabel Durbin Watson dengan nilai Durbin Watson hasil perhitungan. Untuk uji 2 arah.

$\mathrm{H}_{1}: \rho \neq 0$. Tolak $\mathrm{H}_{0}$ pada taraf $2 \alpha$ jika $\mathrm{d}<\mathrm{du}$ atau $4-\mathrm{d}<\mathrm{du}$

$\mathrm{N}($ besar sampel $)=30, \mathrm{k}($ variabel independen $)$ $=1$

Nilai Durbin Watson dari perhitungan $(\mathrm{d})=$ 2.11
Nilai Durbin Watson pada tabel untuk du $=1.49$ (lihat tabel Durbin Watson)

$2.11>1.49$ atau $4-2.11>1.49 \rightarrow 1.89>1.49$.

Kesimpulan : karena $\mathrm{d}>\mathrm{du}$ atau $4-\mathrm{d}>\mathrm{du}$, maka terima Ho. Artinya tidak ada korelasi antar residu.

4. Tidak ada multikolinieritas

Karena variabel independen hanya satu, uji asumsi multikolinieritas tidak bisa dilakukan.

5. Linieritas

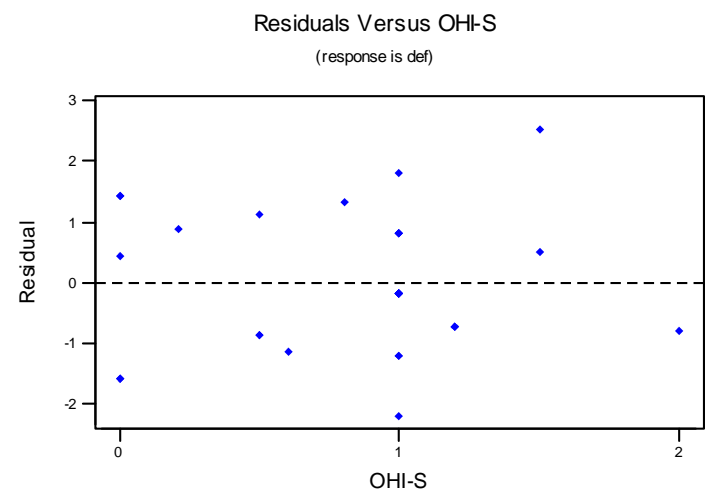

Dari gambar diatas : Titik-titik plot tersebar disekitar nilai 0 , dikatakan terdapat linieritas Pada uji varians dihasilkan P-Value $=0.000$.

Pada uji t nilai "P-Value" untuk variabel OHI-S signifikan ("Sig" $=0.000$ ).

Sehingga dapat disimpulkan bahwa variabel OHI-S berpengaruh signifikan dengan variabel karies gigi.

Persamaan regresi yang dihasilkan : Karies = $1.5581+2.6216$ OHI-S.

\section{Pembahasan}

Setelah data dirandom sebanyak 30 dari 100 data sekunder, kemudian di analisis regresi linier ganda, hasil analisis menunjukkan semua asumsi untuk regresi linier ganda terpenuhi. Pada uji varians dihasilkan P-Value $=0.000$. Pada uji t nilai "P-Value" untuk variabel umur tidak signifikan ("Sig" = 0.932), sedangkan "PValue" untuk variabel OHI-S signifikan ("Sig" $=0.000)$. Sehingga variabel umur harus dikeluarkan dari analisis.

Setelah dilakukan analisis regresi linier sederhana dengan satu variabel dependen (karies) dan satu variabel independen (OHI-S), 
ternyata semua asumsi untuk regresi linier sederhana terpenuhi. Pada uji varians dihasilkan P-Value $=0.000$. Pada uji t nilai "P-Value" untuk variabel OHI-S signifikan ("Sig" $=0.000$ ). Sehingga dapat disimpulkan bahwa variabel OHI-S berpengaruh signifikan dengan variabel karies. Persamaan regresi yang dihasilkan : Karies $($ def $)=1.5581+2.6216$ OHI-S. Artinya setiap kenaikan satu satuan OHI-S maka karies akan bertambah 2.6216 satuan.

Faktor Penyebab Karies adalah faktor langsung dan faktor tidak langsung. Suwelo (1992), mengemukakan teori tentang faktor utama penyebab karies gigi, yaitu gigi, saliva, mikroorganisme, makanan dan waktu. Sedangkan faktor tidak langsung yang erat hubungannya dengan karies gigi adalah usia, jenis kelamin, letak geografi, ras, sosial ekonomi, perilaku memelihara kesehatan gigi. Perilaku menjaga kebersihan gigi yang jelek berpengaruh terhadap tingkat karies gigi. Tidak selalu anak usia 11 tahun memiliki tingkat karies yang lebih tinggi dari pada anak usia 8 tahun, karena perilaku menjaga kebersihan gigi setiap anak tidak sama. Sehingga variabel umur tidak berpengaruh terhadap variabel karies gigi. Kebersihan gigi yang jelek merupakan salah satu penyebab terjadinya karies gigi sulung maupun gigi permanen, terutama pada anakanak. Semakin baik tingkat kebersihan mulut maka tingkat keparahan karies semakin rendah dan sebaliknya. Hal tersebut akan memperkuat asumsi bahwa kebersihan mulut merupakan salah satu faktor yang berpengaruh terhadap karies. Hal tersebut sesuai dengan penelitian Beal et al (1979) dalam Kuntari (1996), yang menyatakan prevalensi karies gigi akan meningkat pada anak-anak dengan gigi kotor dibanding dengan anak-anak dengan gigi yang bersih.

Glickman (1972) dalam Boediharjo (1989), mengatakan bahwa terdapat hubungan yang kuat antara kebersihan mulut yang jelek, adanya plak dengan prevalensi dan keparahan penyakit periodontal dan karies gigi. Menurut Suomi (1970) dan Starkey (1978) dalam Boediharjo (1989), penyakit periodontal dan penyakit karies gigi dapat dikurangi dengan menjaga gigi dan mulut tetap bersih dari sisa makanan (debris) dan plak sebagai cara yang efektif dalam mencegah penyakit periodontal dan penyakit karies gigi.

\section{Kesimpulan dan Saran}

\section{Kesimpulan}

1. Persamaan regresi linier dikatakan valid, jika semua asumsi regresi linier terpenuhi, begitu juga pada uji $t$ dan uji varians harus signifikan. Jika ada salah satu atau beberapa syarat tidak terpenuhi, maka persamaan regresi yang dihasilkan tidak valid (tidak bisa diaplikasikan). Jika pada uji t terdapat variabel independent yang tidak signifikan, maka dilakukan analisis regresi linier ulang dengan tidak melibatkan variabel tersebut.

2. Pada analisis regresi linier ganda yaitu satu variabel dependen (karies gigi) dan dua variabel independent (umur dan OHI-S) tidak menghasilkan persamaan regresi linier yang valid. Dengan menghilangkan variabel independent (OHI-S) dihasilkan persamaan regresi yang valid

Saran

1. Diharapkan asumsi-asumsi untuk regresi linier dan penggunaan uji $t$ dan uji varians benar-benar diterapkan untuk menghasilkan persamaan regresi yang valid. Kedepannya diharapkan diciptakan alternatif lain jika salah satu atau beberapa asumsi regresi linier tidak terpenuhi.

\section{Daftar Acuan}

1. Boedihardjo, 1989, Pemeliharaan Kesehatan Gigi Keluarga, Majalah Ilmu Kesehatan Gigi, No. 29, Surabaya : Penerbit Press Universitas Airlangga

2. Carranza, F.A., 1990, Glickman's Clinical Periodontology, Seven Edition, Tokyo : W.B. Saunders Company

3. Djarwanto, 1996, Mengenal Beberapa Uji Statistika Dalam Penelitian, Yogjakarta : Liberty

4. Ford, P.T.R., 1993. Restorasi Gigi. Alih Bahasa: Narlan Sumawinata, Judul Asli: The Restoration of Teeth, Jakarta : EGC 
5. Handayani ATW, 2007, Erupsi Gigi Permanen Dan Kesehatan Rongga Mulut Pada Anak Sekolah Dasar Di Daerah Endemik Gondok Kabupaten Jember, Tesis, Surabaya : Fakultas Kesehatan Masyarakat Universitas Airlangga

6. Kidd, E.A.M dan Bechal S.J., 1992., Dasardasar Karies, Alih Bahasa: Narlan Sumawinata, Judul Asli: Essential of Dental Karies, 1987, Jakarta : EGC

7. Kuntari, S, 1996, Hubungan Antara Kebersihan Gigi dan Karies Gigi Pada Anak Usia 4 - 6 Tahun di Kotamadya Surabaya. Dent. J. Vol. 29. No. 1. Surabaya : Majalah Kedokteran Gigi

8. Menzefricke U, 1995, Statistic Of Manager, California : Duxbury Press
9. Neuman, W. Lawrence, 2006, Social Research Methods Qualitative And Quantitative Approach. $6^{\text {th }}$ Edition, Boston : Pearson

10. Newbrun, E., 1978, Cariology, Baltimore: The Williams dan Wilkins Co

11. Suwelo, I.S., 1992, Karies Gigi Pada Anak dengan Pelbagai Faktor Etiologi, Jakarta : Penerbit Buku Kedokteran EGC

12. Tarigan R, 1990, Kesehatan gigi dan Mulut, Jakarta : EGC

13. Wibowo A, dkk., 2006, Analisis Regresi Linier, Ordinal Dan Regresi Logistik, Surabaya : LPPM Unair 